\title{
COMO O PEQUENO INVESTIDOR PODE USAR AS TEORIAS DE GRAHAM E MARKOWITZ
}

\author{
Roque Alberto Zin ${ }^{1}$, Edielson Tarso ${ }^{1}$, \\ ${ }^{1}$ Centro de Ciências Sociais Aplicadas- Universidade de Caxias do Sul - UCS \\ roque@majorem.com.br, edielsontegmail.com
}

\section{RESUMO}

A presença do investidor pessoa física na principal bolsa de valores brasileira tem aumentado nos últimos anos. A grande maioria é composta de pequenos investidores, os quais nem sempre possuem conhecimentos ou recursos para analisar com profundidade os ativos em que pretendem investir. O objetivo deste estudo é verificar a eficiência da aplicação no mercado brasileiro de duas estratégias utilizadas por investidores de sucesso. Bem como, a utilização de uma ferramenta simples para avaliar os ativos e auxiliar na composição de um portfólio de forma a minimizar os riscos. Para tanto, foram utilizadas as teorias Benjamin Grahan para a escolha dos ativos a serem adquiridos, e o modelo da fronteira eficiente de Harry Markowitz para definir a participação de cada ativo na composição das carteiras. Para a realização dos cálculos foi utilizada a planilha eletrônica Excel®, uma ferramenta simples e disponível a todos os investidores. O período estudado foram os anos de 2006 a 2010, ou seja, dois anos anteriores e dois anos posteriores a crise mundial de 2008. No inicio do período foram formadas cinco carteiras conforme os filtros de Grahan e a participação de cada ativo foi estabelecida conforme os critérios demonstrados por Markowitz. Os ativos que compõem a carteira bem como a sua participação no total investido são avaliados e alterados uma única vez no inicio de cada ano. Os resultados, no final do período analisado, mostram que é possível minimizar os riscos e obter retornos superiores ao índice Ibovespa, compondo carteiras com pequeno número de ativos e fazendo somente uma movimentação por ano, o que simplifica o acompanhamento e reduz os custos de transação.

Palavras Chaves: Finanças. Investimentos. Seleção de Carteiras. Fronteira eficiente. Pequeno investidor.

\section{HOW THE SMALL INVESTOR CAN USE THE THEORIES OF GRAHAM AND MARKOWITZ}

\section{ABSTRACT}

The presence of individual investors in the main Brazilian stock exchange has increased in recent years. The vast majority are small investors who do not always have knowledge or resources to analyze in depth the assets in which they invest. The aim of this study is to verify the efficiency of the application in the Brazilian market of two strategies used by successful investors. As well, the use of a simple tool to evaluate and active assist in the composition of a portfolio to minimize the risks. To do so, the theories Benjamin Graham to choose the assets to be acquired, and the model of Harry Markowitz efficient frontier were used to define the contribution of each asset in the portfolio composition. For the calculations to Excel $®$ spreadsheet was used, a simple and affordable tool for all investors. The study period were the 
years 2006 to 2010, ie two years prior and two years following the global crisis of 2008. At the beginning of the period were formed five portfolios as filters Graham and the share of each asset was established as the criteria stated by Markowitz. The assets comprising the portfolio as well as its share in total investment are evaluated and changed only once at the beginning of each year. The results at the end of the analyzed period, show that it is possible to minimize risk and get higher returns to the Bovespa index, composing portfolios with few assets and making only one drive per year, which simplifies monitoring and reduces transaction costs .

Keywords: Finance. Investmets. Portfólio Selection. Efficient Frontier. Small investor

\section{RESUMEN}

La presencia de los inversores individuales en la principal bolsa de valores de Brasil ha aumentado en los últimos años. La gran mayoría son pequeños inversores que no siempre tienen los conocimientos ni los recursos para analizar en profundidad los activos en los que invertir. El objetivo de este estudio es verificar la eficacia de la aplicación en el mercado brasileño de dos estrategias utilizadas por los inversores de éxito. Así como el uso de una herramienta simple para evaluar y ayudar en la composición activa de una cartera para minimizar los riesgos. Para ello, las teorías de Benjamin Graham a la selección de los activos a ser adquiridos, y el modelo de Harry Markowitz frontera de eficiencia se utilizaron para definir la contribución de cada activo de la composición de la cartera. Para los cálculos de Excel ${ }^{\circledR}$ se utilizó hoja de cálculo, una herramienta simple y accesible para todos los inversores. El período estudiado fueron los años 2006 a 2010, es decir dos años antes y dos años después se formó la crisis mundial de $2008 \mathrm{Al}$ comienzo del período de cinco carteras como filtros de Graham y la participación de cada activo se estableció como el criterios enumerados por Markowitz. Los activos que componen la cartera, así como su participación en la inversión total se evalúan y cambian sólo una vez al comienzo de cada año. Los resultados al final del período analizado, muestran que es posible minimizar el riesgo y obtener más altos que los rendimientos del índice Bovespa, componer carteras con pocos activos y haciendo sólo una unidad por año, lo que simplifica el monitoreo y reduce los costos de transacción .

Palabras claves: Finanzas. Inversiones. Selección de Carteras. Frontera eficiente. Pequeño inversor.

\section{Introdução}

No processo de administrar os recursos e alocar os investimentos é muito importante fazer a analise dos ativos a serem adquiridos. O segundo ponto importante é conhecer e administrar os riscos inerentes.

Os investimentos em ações de empresas cresceram consideravelmente nos últimos anos e a participação das pessoas físicas nos negócios também tem aumentado significativamente. Conforme a Bovespa (2011) o número de CPFs cadastrados cresceu $157,63 \%$ no período de 2002 a 2006, passando de 85.249 para 219.634. E no período de 2006 a 2010, o volume de investidores passou para 610.695 o que significa um crescimento acumulado de $616,36 \%$.

Esse crescimento pode ser explicado pela valorização dos ativos a partir de 2002 e a queda das taxas de juros na renda fixa. Porém, a partir da crise de 2008 ocorreu uma desvalorização acentuada das empresas listadas em bolsa. Considerando o aumento da volatilidade dos ativos e a maior participação dos investidores individuais, surge o questionamento de como ele poderia investir minimizando os riscos. Nesse contexto é 
proposto o uso de ferramentas que permitam a seleção dos ativos e a análise de riscos. $\mathrm{O}$ período analisado envolve dois anos antes da crise americana de 2008 e dois anos posteriores.

No que diz respeito a analise de fundamentos de ações o nome de Benjamin Graham é considerado o maior analista de investimentos que já existiu, pois aliava o conhecimento teórico à sua pratica de atuação no mercado. Sendo um dos poucos investidores a ter uma vida acadêmica. O seu método era puramente quantitativo e utilizava as informações que estavam a disposição de todos.

Sob o aspecto dos riscos nos investimentos, um dos primeiros acadêmicos a considerar a sua importância foi Harry Markowitz. De acordo com o modelo desenvolvido, o retorno esperado para um grupo de ativos é a média ponderada do retorno esperado de cada ativo individual. Por outro lado, o risco não era a média dos riscos dos ativos que compõem o portfólio, mas uma função das variâncias de cada ativo e como eles estavam correlacionados.

O objetivo deste trabalho é avaliar a rentabilidade de um portfólio de ações, onde os ativos foram escolhidos conforme os critérios fundamentalistas de Benjamin Graham e a participação dos ativos dentro do portfólio foi estabelecida de acordo com o risco calculado conforme o modelo de Markowitz. Com base na teoria destes dois autores foram construídas carteiras de ações. Com esta abordagem foi possível comparar a rentabilidade com o índice de mercado (Ibovespa) e com a aplicação em renda fixa. $\mathrm{O}$ artigo está estruturado da seguinte forma, além desta introdução, são apresentadas as teorias dos dois autores, a seguir são apresentados os procedimentos metodológicos e o desempenho de cada carteira, em seguida são feitas as considerações finais sobre o trabalho.

\section{A visão dos dois autores}

Graham e Markowitz são dois dos nomes mais respeitados e conhecidos no Mercado financeiro mundial. Graham é considerado pelos profissionais do mercado financeiro, um dos melhores investidores que já existiram e o maior analista de investimentos práticos de todos os tempos. Markowitz por sua vez definiu em sua teoria que os investidores podem determinar todas as carteiras ótimas no sentido risco e retorno e formar a fronteira eficiente a qual pode ser descrita como o melhor conjunto possível de carteiras, isto é, todas as carteiras têm o mínimo nível de risco para dado nível de retorno. Neste capitulo iremos colocar os pontos principais das duas teorias.

\subsection{Benjamin Graham}

Benjamim Graham é considerado como o precursor da estratégia buy and hold (compre e segure). Sua estratégia consistia em comprar ações de empresas sólidas e com ótimas perspectivas de geração de caixa, mantendo-as em carteira por um longo período com a finalidade de maximizar os lucros, reduzindo os custos de transação.

Publicou em 1934 com o Professor David L. Dodd, o livro "Security Analysis" e anos mais tarde o seu livro mais difundido no mercado financeiro, O Investidor Inteligente (The Inteligent Investor), no qual estão publicadas suas metodologias que serão aplicados no presente estudo.

É considerado o mentor de Warren Buffet, que, conforme Schoreder (2008) reverenciava suas ideias. Para Graham (2007) o investidor não tinha escolha a não ser correr algum risco no mercado de ações, senão ele corre um risco maior de manter "apenas instrumentos de renda fixa" (p. 592). Entre os principais riscos apontados estão o de pagar um preço alto por ações de boa qualidade e compra de papéis de baixa qualidade numa conjuntura favorável.

Entre os principais conceitos adotados por Graham (2007) estão os de que o mercado oferece todos os dias ações a preços diferentes, as vezes o preço é alto, as vezes é baixo,porém, e nenhum investidor é obrigado a aceitar a proposta do mercado. Outra de suas 
afirmações é que a ação representa um negócio, portanto o investidor deveria identificar as características importantes num negócio.

Um conceito chave para Graham (1973) era a margem de segurança, que definia a diferença entre investimentos e especulação, segundo esse conceito um ativo deve possuir um valor maior que seu custo, quanto menor o custo em relação ao valor maior a segurança no futuro em relação as quedas dos lucros. As suas análises eram realizadas por métodos quantitativos, principalmente preço em relação ao lucro $(\mathrm{P} / \mathrm{L})$ e preço em relação ao valor contábil (P/VC). A diversificação deve ser adequada para minimizar os riscos, porém, não deve ser excessiva para evitar os custos de transação. A sugestão para o mercado americano era de "mínimo de dez ações diferentes e um máximo de aproximadamente trinta" (p. 137)

\subsection{Harry Markowitz}

Harry Markowitz publicou em 1952, seu artigo, "Portfolio Selection" apresentando as bases para a moderna teoria de carteiras onde estabeleceu que um portfólio de investimento, para ser eficiente, deveria possuir o maior índice de retorno para determinado nível de risco. Afirmou que é possível identificar estes portfólios eficientes utilizando apenas três informações: a taxa de retorno dos ativos integrantes da carteira, a variância das taxas de retornos e a covariância entre todas as taxas de retorno.

Segundo Vince (1999), a diversificação só se mostra eficiente enquanto o coeficiente de correlação entre os sistemas de mercado envolvidos for negativo. $\mathrm{O}$ autor destaca a grande importância da diversificação na composição de uma carteira de investimentos, onde, segundo Markowitz, permite a redução e até mesmo a eliminação total do risco não-sistemático de um portfólio. A teoria parte das seguintes premissas:

a) Os investidores avaliariam as carteiras apenas com base no retorno esperado e no desvio padrão dos retornos sobre o horizonte de tempo de um período;

b) Os investidores seriam avessos ao risco. Quanto postos a escolher entre duas carteiras com o mesmo retorno, sempre escolheriam de menor risco;

c) Os investidores estariam sempre insatisfeitos. Quando postos a escolher entre dois portfólios com o mesmo risco, escolheriam o com o maior retorno;

d) Seria possível dividir os ativos;

e) Existiria uma taxa livre de risco, na qual os investidores poderiam tanto emprestar, quanto tomar emprestado;

f) Todos os custos de transação e impostos seriam irrelevantes;

g) Os investidores estariam de acordo em relação à distribuição de probabilidade de taxas de retorno dos ativos, o que asseguraria a existência de um único conjunto de carteiras eficientes.

\subsection{Estudos no Brasil}

No Brasil, Passos (2006) verificou a aplicabilidade das teorias de Graham no mercado acionário brasileiro, no período de 1994 a 2000 foi criada uma carteira para os anos seguintes. No período de 5 anos a carteira teve um retorno de $566 \%$ enquanto o Ibovespa obteve um crescimento de $219 \%$.

Um estudo envolvendo o período de 1997 a 2001 no mercado brasileiro foi elaborado por Salgueiro (2007) o resultado foi uma rentabilidade acumulado de $646,65 \%$ na carteira com os filtros de Graham quando o Ibovespa rendeu 277,56\% no mesmo período.

Passos e Pinheiro (2009) aplicaram os filtros de Graham em duas carteiras de ações com base nos históricos de cinco e doze anos anteriores. No período de 2001 a 2005 a carteira com prazos mais longos não se mostrou tão eficiente, mas a carteira com base nos dados dos últimos 5 anos obteve um rendimento de 2,5 vezes superior ao Ibovespa. 
Artuso e Chaves Neto (2010) testaram os filtros no período de 1998 a 2009 e mostraram que os resultados podem ser superiores aos indicadores de mercado principalmente para as carteiras com prazos mais longos. No entanto, revelam a preocupação com o pequeno numero de empresas o que resulta em pouca diversificação.

Silva \& Stern (1995) aplicaram o modelo de Markowitz no mercado brasileiro e concluíram que o índice Bovespa não é eficiente gerando algumas dúvida no uso desse indicador como referencia do mercado de ações brasileiros. Esse resultado foi confirmado por Nakamura (2000) que testou a carteira teórica do índice Bovespa e concluiu que não se baseia na fronteira eficiente de Markowitz, podendo ser formados portfólios mais eficientes do ponto de vista da média-variância.

Zanini e Figueiredo (2005) testaram as teorias de Markowitz e Sharpe no mercado brasileiro no período de 1995 a 2000 e não encontraram evidências de superioridade no desempenho de uma relação a outra. Com relação a carteira de mercado o desempenho foi idêntico do ponto de vista estatístico. Donde eles concluem que haveria vantagens para o investidor na utlização deste modelos.

\section{Características do índice Bovespa}

O índice Bovespa é o valor atual, em moeda corrente, de um portfólio hipotético de ações que iniciou em 1968 com o valor teórico de 100. As ações que fazem parte do portfólio, bem como, sua participação relativa, são revisadas a cada quatro meses. $\mathrm{O}$ critério para fazer parte do portfólio são a liquidez e a capitalização. O numero de ações deve responder por $80 \%$ dos negócios e do volume financeiro no mercado a vista. Quando foi criado, índice Bovespa era composto por 27 ações, no final do ano de 2010 era composto por 68 ações.

\section{Metodologia}

Para avaliar a aplicabilidade das teorias foi utilizada a base de dados do software Economática, a qual contém os dados detalhados empresas com ações negociadas na BM\&FBovespa.

O prazo de análise das ações foi de 5 anos anteriores a formação da carteira. Uma vez escolhidos os papéis e a composição da carteira, o investimento ficaria mantido até o final do ano, quando uma nova analise com base nos 5 anos anteriores resultaria numa nova composição.

\subsection{Processo de seleção de ativos}

O processo de seleção de ativos aplica as ideias propostas por Graham, como o histórico de múltiplos e os históricos operacionais, determinando que ações do mercado brasileiro são uma boa oportunidade de compra. Para tanto, foram definidas as seguintes premissas:

a) O período de análise serão os cinco anos anteriores à data de formação da carteira;

b) Serão utilizados sempre os preços de fechamento das ações ajustados por dividendos;

c) Para múltiplos que dependem da apuração de balanços anuais, como lucro líquido, sabendo-se que o estudo irá representar o investimento como alocado sempre no primeiro dia útil do ano seguinte ao último ano de estudo e nesta data ainda não temos esta informação disponível, serão utilizados para estes múltiplos os valores acumulados até o terceiro trimestre do ano anterior ao de alocação.

Estabelecidas as premissas, iniciou-se o processo de geração das carteiras, buscando sempre a compra de ativos por um preço considerado inferior ao seu valor intrínseco, isto é, que o valor das ações adquiridas seja inferior ao valor contábil da empresa. 
Os múltiplos analisados na formação das carteiras foram: Volume Negociado, Rentabilidade sobre o Patrimônio Líquido, Lucro Líquido, P/L (preço sobre o lucro), P/VPA (preço sobre o valor patrimonial da ação) e Liquidez Corrente.

Depois de identificados os múltiplos, foram definidos os parâmetros utilizados como filtros na composição da nossa carteira. Estes foram adaptados de sua literatura original, escrita em 1973, para nossa realidade a fim de identificarmos empresas que não estejam supervalorizadas e com perspectiva de crescimento.

Foram definidos os seguintes filtros:

a) Média do volume negociado nos últimos doze meses superior a $\mathrm{R} \$ 20.000 .000$;

b) Rentabilidade sobre o patrimônio líquido médio dos últimos cinco anos superior a 10 ;

c) Lucro líquido em 31/12 do ano anterior ao último período analisado, superior ao de cinco anos atrás;

d) Ter obtido lucro líquido positivo nos últimos cinco anos anteriores ao último ano analisado;

e) Ter obtido lucro líquido acumulado positivo no terceiro trimestre do ano anterior ao de alocação;

f) $\quad \mathrm{O} / \mathrm{L}$ no terceiro trimestre do ano anterior ao de alocação deve ser superior a 0 e inferior a 20 ; a 3 ;

g) O P/VPA no terceiro trimestre do ano anterior ao de alocação deve ser inferior

h) A Liquidez Corrente no terceiro do ano anterior ao de alocação deve ser superior a 1 ;

Os resultados estão demonstrados na figura 1. Para cada ano há uma carteira de ativos conforme a teoria de Graham.

\begin{tabular}{|l|l|l|l|l|}
\hline Ano 2006 & Ano 2007 & Ano 2008 & Ano 2009 & Ano 2010 \\
\hline BBDC4 & GGBR4 & BRFS3 & CPLE6 & BBDC4 \\
\hline GGBR4 & GOAU4 & GGBR4 & GFSA3 & BRAP4 \\
\hline PETR4 & PETR4 & GOAU4 & CYRE3 & CMIG4 \\
\hline & VALE5 & PETR4 & GGBR4 & USIM5 \\
\hline & & & GOAU4 & PETR4 \\
\hline & & & TNLP4 & VALE5 \\
\hline & & & USIM5 & RSID3 \\
\hline & & & VALE5 & \\
\hline
\end{tabular}

Figura 1 - Composição das carteiras anuais resultantes da aplicação da metodologia Graham

Fonte: Elaborado pelos autores

\subsection{Alocação de recursos}

Os conceitos descritos pela teoria moderna do portfólio propõem que ele deve se basear em composição e não em seleção individual de ações (VINCE 2004). Após a identificação dos ativos foi utilizada a teoria de Harry Markowitz, para encontrar a melhor composição dos portfólios que resulta na melhor relação risco/retorno.

\subsubsection{Risco e retornos dos ativos}


Para identificar a carteira eficiente, foi calculado o retorno de cada ativo, tomando por base a cotação de fechamento nos dois anos anteriores à data inicial da alocação no portfólio, ajustadas por proventos, desdobramentos e agrupamentos. Todos os dados foram retirados da base de dados do software Economática.

Para o cálculo do retorno dos ativos, utilizou-se a biblioteca de funções para Excel disponibilizado pela Risckteck, empresa especializada no gerenciamento de risco em investimento.

Além do retorno dos ativos que compõem a carteira, calculou-se o retorno do índice Ibovespa no mesmo período, com isso é possível calcular os excessos de retorno dos ativos em relação ao índice da bolsa de valores.

A tabela 1 mostra os ativos selecionados em 2006. As três empresas tem taxas de risco semelhantes, mas com diferenças significativas nos retornos. A empresa com maior retorno (BBDC4) apresenta o maior risco. A empresa com menor retorno (PETR4) apresenta o menor risco.

Tabela 1 - Risco e retorno dos ativos da carteira com alocação em 2006

\begin{tabular}{l|l|l}
\hline Ativo & Retorno & Risco \\
\hline BBDC4 & $40,93 \%$ & $25,41 \%$ \\
\hline GGBR4 & $21,66 \%$ & $24,14 \%$ \\
\hline PETR4 & $18,01 \%$ & $19,87 \%$ \\
\hline
\end{tabular}

A tabela 2, relativa aos ativos selecionados para o ano de 2007, apresenta uma variação pequena no risco dos ativos, porém, a variação do retorno foi elevada, revelando a necessidade de ajustes na composição da carteira.

Tabela 2 - Risco e retorno dos ativos da carteira com alocação em 2007

\begin{tabular}{l|l|l}
\hline Ativo & Retorno & Risco \\
\hline GGBR4 & $4,75 \%$ & $23,22 \%$ \\
\hline GOAU4 & $0,09 \%$ & $24,14 \%$ \\
\hline PETR4 & $15,81 \%$ & $19,87 \%$ \\
\hline VALE5 & $3,29 \%$ & $20,96 \%$ \\
\hline
\end{tabular}

Nos ativos selecionados para o ano de 2008, conforme demonstrado na tabela 3 , houve uma variação maior nos riscos. A extensão foi de 19,92 a 46,03. Ocorreu também grande variação nos retornos. A ação Goau4 teve retorno negativo de $54,72 \%$ e a Petr4 teve o maior retorno com $14,91 \%$.

Tabela 3 - Risco e retorno dos ativos da carteira com alocação em 2008

\begin{tabular}{l|l|l}
\hline Ativo & Retorno & Risco \\
\hline BRFS3 & $2,10 \%$ & 42,61 \\
\hline GGBR4 & $6,21 \%$ & 19,92 \\
\hline GOAU4 & $-54,72 \%$ & 46,03 \\
\hline PETR4 & $14,91 \%$ & 21,05 \\
\hline
\end{tabular}


A seleção dos ativos para o ano de 2009 foi realizada com os reflexos da crise do subprime que afetou o mercado de ações. Conforme a tabela 4 foram selecionados oito ativos.

Tabela 4 - Risco e retorno dos ativos da carteira com alocação em 2009

\begin{tabular}{l|l|l}
\hline Ativo & Retorno & Risco \\
\hline CPLE6 & $10,12 \%$ & $32,73 \%$ \\
\hline GFSA3 & $-39,33 \%$ & $54,56 \%$ \\
\hline CYRE3 & $-26,55 \%$ & $51,55 \%$ \\
\hline GGBR4 & $4,60 \%$ & $27,93 \%$ \\
\hline GOAU4 & $8,84 \%$ & $30,60 \%$ \\
\hline TNLP4 & $21,75 \%$ & $40,00 \%$ \\
\hline USIM5 & $1,01 \%$ & $32,27 \%$ \\
\hline VALE5 & $5,76 \%$ & $22,54 \%$ \\
\hline
\end{tabular}

A seleção dos ativos para o ano de 2010, conforme demonstrado na tabela 5, foi a que teve o maior numero de ativos e sua composição e também a que apresentou o maior numero de ativos com retorno negativo.

Tabela 5 - Risco e retorno dos ativos da carteira com alocação em 2010

\begin{tabular}{l|l|l}
\hline Ativo & Retorno & Risco \\
\hline BBDC4 & $0,34 \%$ & $24,24 \%$ \\
\hline BRAP4 & $-9,46 \%$ & $29,43 \%$ \\
\hline CMIG4 & $12,45 \%$ & $36,94 \%$ \\
\hline USIM5 & $-3,27 \%$ & $33,14 \%$ \\
\hline PETR4 & $-8,95 \%$ & $25,15 \%$ \\
\hline VALE5 & $-8,61 \%$ & $22,19 \%$ \\
\hline RSID3 & $-18,35 \%$ & $61,61 \%$ \\
\hline
\end{tabular}

\subsubsection{Correlação entre os ativos das carteiras}

Utilizando-se a ferramenta de análise de dados do Excel, correlação, calculou-se a matriz de correlação dos ativos de cada carteira, tomando-se como base os dados dos excessos de retorno dos ativos em relação ao retorno do Ibovespa nos dois anos anteriores a data inicial de alocação da carteira.

\subsubsection{Montagem da matriz de covariância}

De posse dos valores das correlações, risco e retorno dos ativos que compõem as carteiras, foi criada para cada carteira a matriz de variância quadrada, a qual é calculada da seguinte forma: $\mathrm{O}$ índice de correlação de um determinado ativo é multiplicado pelo seu risco e pelo risco do ativo com o qual se queira obter a covariância. 


\subsubsection{Retorno da carteira}

A teoria do portfólio trata da composição da carteira de ativos, tendo como objetivo principal maximizar o grau de satisfação do investidor através da relação risco/retorno.

Para efetuar o cálculo das quantidades alocadas em cada ativo a fim de obter a melhor relação risco/retorno, primeiramente deve-se desenvolver o método de cálculo dos dois índices bem como da relação entre eles.

O retorno da carteira foi obtido, calculando-se a média ponderada dos retornos dos ativos que compõem a carteira, considerando-se o percentual de representação do ativo na carteira.

\subsubsection{Risco da carteira}

Segundo Assaf Neto (2003), para o cálculo do risco de um portfólio, é necessário levar em consideração, não somente a participação e o risco de cada ativo individualmente, mas também como os ativos se correlacionam.

Em um processo de diversificação, elevando-se o número de títulos em uma carteira é possível que se promova uma redução em seu risco total se comparado ao risco calculado para cada um dos componentes da carteira. Para surtir este efeito, basta que os retornos dos ativos não sejam perfeita e positivamente correlacionados entre si.

A diversificação permite a redução do risco da carteira, porém, não sua eliminação, pois dificilmente se encontram no mercado ativos com correlação negativa perfeita. .

Para aplicar a expressão de cálculo de risco nas carteiras, realizamos o cálculo em dois momentos. Primeiramente obtivemos a covariância de cada ativo, considerando-se a quantidade alocada na carteira e realizamos o somatório da covariância de cada ativo onde obtemos a covariância da carteira. Posteriormente, obtivemos o desvio padrão ou risco da carteira, extraído a raiz quadrada da covariância.

\subsubsection{Aplicação do modelo de Markowitz}

A utilização do modelo de Markowitz para definir a composição de um portfólio de ativos, consiste, em buscar uma carteira que possua a melhor relação retorno/risco, seguindo a constatação de Elton et al. (2004), onde afirma que, a existência de uma taxa livre de risco faz com que haja uma única carteira de ativos que seja preferível as demais.

Neste estudo foi utilizado a ferramenta Solver do Excel, para identificar que percentual de alocação em cada ativo resultará no portfólio eficiente, bem como para determinar os extremos da fronteira eficiente.

Foram criadas as carteiras para cada ano. A carteira considerada eficiente foi denominada de "MARKOWITZ" e as carteiras 1 e 5, seus extremos. As demais carteiras são as intermediárias.

Tabela 6 - Alocações de ativos para a carteira no ano de 2006

\begin{tabular}{l|l|l|l|l|l}
\hline & \multicolumn{5}{c}{ Carteiras } \\
\hline Ativos & $\mathbf{1}$ & $\mathbf{2}$ & MARKOWITZ & $\mathbf{4}$ & $\mathbf{5}$ \\
\hline BBDC4 & $20,00 \%$ & $25,00 \%$ & $39,93 \%$ & $60,00 \%$ & $100,00 \%$ \\
\hline GGBR4 & $40,00 \%$ & $45,00 \%$ & $29,29 \%$ & $30,00 \%$ & $0,00 \%$ \\
\hline PETR4 & $40,00 \%$ & $30,00 \%$ & $30,77 \%$ & $10,00 \%$ & $0,00 \%$ \\
\hline Risco & $\mathbf{1 2 , 9 7}$ & $\mathbf{1 3 , 3 9}$ & $\mathbf{1 2 , 9 2}$ & $\mathbf{1 6 , 6 2}$ & $\mathbf{2 5 , 4}$ \\
\hline Retorno & $\mathbf{2 4 , 0 5}$ & $\mathbf{2 5 , 3 8}$ & $\mathbf{2 8 , 2 3}$ & $\mathbf{3 2 , 8 5}$ & $\mathbf{4 0 , 9 3}$ \\
\hline Retorno/Risco & $\mathbf{1 , 8 5}$ & $\mathbf{1 , 9 7}$ & $\mathbf{2 , 1 8}$ & $\mathbf{1 , 9 7}$ & $\mathbf{1 , 6 1}$ \\
\hline
\end{tabular}


Para o ano de 2006, a carteira com apenas três ativos, mostrada na tabela 6 , teve retorno de $28,23 \%$ no ano com um risco de $12,92 \%$. Conforme pode ser observado, a carteira denominada de "Markowitz" resultou na melhor relação retorno e risco com 2,18.

Para o ano de 2007, conforme pode ser observado na tabela 7 a carteira tem 4 ativos, porém a maximização do retorno em relação ao risco, fica com apenas dois ativos. A fronteira eficiente gera uma taxa de retorno de $13,32 \%$ no ano e risco de $15,83 \%$ o que resulta numa relação de 0,84 .

Tabela 7 - Alocações de ativos para a carteira no ano de 2007

\begin{tabular}{l|l|l|l|l|l}
\hline & \multicolumn{5}{|c}{ Carteiras } \\
\hline Ativos & $\mathbf{1}$ & $\mathbf{2}$ & MARKOWITZ & $\mathbf{4}$ & $\mathbf{5}$ \\
\hline GGBR4 & $20,00 \%$ & $20,00 \%$ & $22,39 \%$ & $5,00 \%$ & $0,00 \%$ \\
\hline GOAU4 & $20,00 \%$ & $0,00 \%$ & $0,00 \%$ & $0,00 \%$ & $0,00 \%$ \\
\hline PETR4 & $50,00 \%$ & $70,00 \%$ & $77,61 \%$ & $90,00 \%$ & $100,00 \%$ \\
\hline VALE5 & $10,00 \%$ & $10,00 \%$ & $0,00 \%$ & $5,00 \%$ & $0,00 \%$ \\
\hline Risco & $\mathbf{1 2 , 9 2}$ & $\mathbf{1 4 , 9}$ & $\mathbf{1 5 , 8 3}$ & $\mathbf{1 8 , 0 8}$ & $\mathbf{1 9 , 8 7}$ \\
\hline Retorno & $\mathbf{9 , 1 9}$ & $\mathbf{1 2 , 3 4}$ & $\mathbf{1 3 , 3 2}$ & $\mathbf{1 4 , 6 2}$ & $\mathbf{1 5 , 8}$ \\
\hline Retorno/Risco & $\mathbf{0 , 7 1 9}$ & $\mathbf{0 , 8 2 7}$ & $\mathbf{0 , 8 4}$ & $\mathbf{0 , 8 0}$ & $\mathbf{0 , 7 9 5 4}$ \\
\hline
\end{tabular}

Para o ano de 2008 a carteira resultou na substituição de uma das ações em relação ao ano de 2007. Conforme a tabela 8 a alocação foi somente em 3 ativos e a relação risco e retorno permaneceu em 0,84 .

Tabela 8 - Alocações de ativos para a carteira no ano de 2008

\begin{tabular}{l|l|l|l|l|l}
\hline & \multicolumn{5}{|c}{ Carteiras } \\
\hline Ativos & $\mathbf{1}$ & $\mathbf{2}$ & MARKOWITZ & $\mathbf{4}$ & $\mathbf{5}$ \\
\hline BRFS3 & $20,00 \%$ & $10,00 \%$ & $8,02 \%$ & $0,00 \%$ & $0,00 \%$ \\
\hline GGBR4 & $30,00 \%$ & $30,00 \%$ & $32,99 \%$ & $20,00 \%$ & $0,00 \%$ \\
\hline GOAU4 & $10,00 \%$ & $10,00 \%$ & $0,00 \%$ & $0,00 \%$ & $0,00 \%$ \\
\hline PETR4 & $30,00 \%$ & $50,00 \%$ & $58,99 \%$ & $80,00 \%$ & $100,00 \%$ \\
\hline Risco & $\mathbf{1 1 , 4 1}$ & $\mathbf{1 2 , 6 4}$ & $\mathbf{1 2 , 9 8}$ & $\mathbf{1 6 , 7 6}$ & $\mathbf{2 1 , 0 4}$ \\
\hline Retorno & $\mathbf{1 , 2 8}$ & $\mathbf{4 , 4 6}$ & $\mathbf{1 1 , 0 1}$ & $\mathbf{1 3 , 1 6}$ & $\mathbf{1 4 , 9}$ \\
\hline Retorno/Risco & $\mathbf{0 , 1 1 2 5}$ & $\mathbf{0 , 3 3 9 6}$ & $\mathbf{0 , 8 4}$ & $\mathbf{0 , 7 8 5 3}$ & $\mathbf{0 , 7 0 8 2}$ \\
\hline
\end{tabular}

A tabela 9 mostra que para o ano de 2009 foram selecionados oito ativos, o dobro de ações do ano anterior. Ao se alocar os ativos conforme a teoria da fronteira eficiente, a carteira ficaria composta com somente cinco ações. 
Tabela 9 - Alocações de ativos para a carteira no ano de 2009

\begin{tabular}{l|l|l|l|l|l}
\hline & \multicolumn{5}{|c}{ Carteiras } \\
\hline Ativos & $\mathbf{1}$ & $\mathbf{2}$ & MARKOVITZ & $\mathbf{4}$ & $\mathbf{5}$ \\
\hline CPLE6 & $19,51 \%$ & $15,00 \%$ & $17,49 \%$ & $0,00 \%$ & $0,00 \%$ \\
\hline GFSA3 & $4,81 \%$ & $0,00 \%$ & $0,00 \%$ & $0,00 \%$ & $0,00 \%$ \\
\hline CYRE3 & $4,59 \%$ & $0,00 \%$ & $0,00 \%$ & $0,00 \%$ & $0,00 \%$ \\
\hline GGBR4 & $11,62 \%$ & $15,00 \%$ & $0,00 \%$ & $0,00 \%$ & $0,00 \%$ \\
\hline GOAU4 & $1,29 \%$ & $10,00 \%$ & $18,50 \%$ & $30,00 \%$ & $0,00 \%$ \\
\hline TNLP4 & $12,15 \%$ & $20,00 \%$ & $27,27 \%$ & $70,00 \%$ & $100,00 \%$ \\
\hline USIM5 & $9,69 \%$ & $0,00 \%$ & $0,03 \%$ & $0,00 \%$ & $0,00 \%$ \\
\hline VALE5 & $36,35 \%$ & $40,00 \%$ & $36,71 \%$ & $0,00 \%$ & $0,00 \%$ \\
\hline Risco & $\mathbf{1 1 , 1 4}$ & $\mathbf{1 3 , 0 1}$ & $\mathbf{1 4 , 0 7}$ & $\mathbf{2 8 , 6 4}$ & $\mathbf{4 0}$ \\
\hline Retorno & $\mathbf{4 , 3 4}$ & $\mathbf{9 , 7 4}$ & $\mathbf{1 1 , 4 5}$ & $\mathbf{1 7 , 8 7}$ & $\mathbf{2 1 , 7 5}$ \\
\hline Retorno/Risco & $\mathbf{0 , 3 9}$ & $\mathbf{0 , 7 4}$ & $\mathbf{0 , 8 1 3 5}$ & $\mathbf{0 , 6 2 4}$ & $\mathbf{0 , 5 4 3 7}$ \\
\hline
\end{tabular}

Para o ano de 2010 foram selecionadas sete ações. Conforme pode ser observado na tabela 10 a carteira mais eficiente na relação risco e retorno teria somente 2 ativos e seria fortemente concentrada numa única empresa com $99,54 \%$ dos recursos.

Tabela 10 - Alocações de ativos para a carteira no ano de 2010

\begin{tabular}{l|l|l|l|l|l}
\hline \multirow{2}{*}{ Ativos } & \multicolumn{5}{c}{ Carteiras } \\
\hline BBDC4 & $\mathbf{1}$ & $\mathbf{2}$ & $\mathbf{4}$ & MARKOWITZ & $\mathbf{5}$ \\
\hline BRAP4 & $0,00 \%$ & $10,00 \%$ & $10,00 \%$ & $0,46 \%$ & $0,00 \%$ \\
\hline CMIG4 & $30,00 \%$ & $10,00 \%$ & $0,00 \%$ & $0,00 \%$ & $0,00 \%$ \\
\hline USIM5 & $20,00 \%$ & $70,00 \%$ & $90,00 \%$ & $99,54 \%$ & $100,00 \%$ \\
\hline PETR4 & $10,00 \%$ & $0,00 \%$ & $0,00 \%$ & $0,00 \%$ & $0,00 \%$ \\
\hline VALE5 & $0,00 \%$ & $0,00 \%$ & $0,00 \%$ & $0,00 \%$ & $0,00 \%$ \\
\hline RSID3 & $0,00 \%$ & $0,00 \%$ & $0,00 \%$ & $0,00 \%$ & $0,00 \%$ \\
\hline Risco & $\mathbf{2 0 , 7 5}$ & $\mathbf{2 4 , 9 2}$ & $\mathbf{3 3 , 4 2}$ & $\mathbf{3 6 , 7 7}$ & $0,00 \%$ \\
\hline Retorno & $\mathbf{5 , 3 3}$ & $\mathbf{7 , 4 7}$ & $\mathbf{1 1 , 2 3}$ & $\mathbf{1 2 , 3 9}$ & $\mathbf{3 6 , 9 4}$ \\
\hline Retorno/Risco & $\mathbf{0 , 2 5 7}$ & $\mathbf{0 , 2 9 9}$ & $\mathbf{0 , 3 3 6}$ & $\mathbf{0 , 3 3 7}$ & $\mathbf{1 2 , 4 4}$ \\
\hline
\end{tabular}

\subsection{Resultados financeiros}

Para uma melhor apuração da eficácia da aplicação das teorias de Graham e Markowitz no mercado brasileiro, foi simulada a alocação de recursos anualmente em todas as cinco carteiras que representam a fronteira eficiente de cada ano de estudo. $\mathrm{O}$ objetivo é verificar o melhor retorno financeiro. Para comparar simulou-se também alocação de recursos em uma carteira denominada como "Ibovespa", que contempla o desempenho das ações que compõem a carteira teórica que resulta no índice de desempenho do mercado brasileiro. Para esta simulação foram estabelecidas as seguintes premissas: 
a) Foram desconsiderados custos de transação (Corretagem, emolumentos, Imposto de renda);

b) Os preços dos ativos serão atualizados por proventos, dividendos, agrupamentos e desdobramentos;

c) Será alocado um capital inicial de R \$ 100.000,00 em 02/01/2006 em cada carteira;

d) O resultado em valores obtido no final de cada ano será reinvestido no primeiro dia útil no ano posterior na nova carteira.

Na tabela 11 estão demonstrados os resultados financeiros acumulados de cada uma das carteiras, bem como o resultado da carteira "Ibovespa". No acumulado de 5 anos a carteira da fronteira eficiente, denominada de "Markowitz", obteve uma rentabilidade acumulada de $120,23 \%$. Como era de se esperar, não foi a carteira mais rentável, ficando em segundo lugar comparado com as demais, uma vez que pondera o retorno em relação ao risco. Neste quesito, obteve uma rentabilidade bem superior a Ibovespa cuja rentabilidade foi de $88,34 \%$ no período enquanto que a carteira "Markowitz" rendeu 120,23\% ou 31,89 pontos percentuais acima do índice oficial do mercado que é o índice Bovespa.

Tabela 11 - Resultado financeiro acumulado

\begin{tabular}{|c|c|c|c|c|c|c|c|c|}
\hline & 2006 & 2007 & 200 & & 200 & & 2010 & \\
\hline 1 & $36.857,47$ & $\mathrm{R} \$ 233.983,95$ & & $129.517,55$ & $\mathrm{R} \$$ & $99.224,65$ & $\mathrm{R} \$$ & $97.394,83$ \\
\hline 2 & $\mathrm{R} \$ \quad 136.915,21$ & $\mathrm{R} \$ 238.740,50$ & $\mathrm{R} \$$ & $141.413,26$ & $\mathrm{R} \$$ & $226.983,07$ & $\mathrm{R} \$$ & $231.411,72$ \\
\hline MARKOVITZ & $\mathrm{R} \$ \quad 135.876,62$ & $\mathrm{R} \$ 234.998,04$ & $\mathrm{R} \$$ & $137.435,75$ & $\mathrm{R} \$$ & $213.755,05$ & $\mathrm{R} \$$ & $220.236,10$ \\
\hline 4 & $\mathrm{R} \$ 135.343,00$ & $\mathrm{R} \$ 241.903,08$ & $\mathrm{R} \$$ & $136.058,83$ & $\mathrm{R} \$$ & $197.175,23$ & $\mathrm{R} \$$ & $204.128,13$ \\
\hline 5 & $\mathrm{R} \$ \quad 133.037,97$ & $\mathrm{R} \$ 239.420,00$ & $\mathrm{R} \$$ & $131.134,35$ & $\mathrm{R} \$$ & $177.385,93$ & $\mathrm{R} \$$ & $182.721,88$ \\
\hline IBOVESPA & $\mathrm{R} \$ \quad 132.727,49$ & $\mathrm{R} \$ \quad 186.845,63$ & $\mathrm{R} \$$ & $111.693,92$ & $\mathrm{R} \$$ & $190.360,36$ & $\mathrm{R} \$$ & $188.346,56$ \\
\hline
\end{tabular}

\subsection{Análise dos Riscos}

A carteira da fronteira eficiente, denominada de "Markowitz", demonstrou sua utilidade na redução de riscos. Conforme pode ser observado na tabela 11 , com base no investimento inicial, no ano de 2008 apesar da crise internacional ela encerrou o ano com uma rentabilidade de $37,43 \%$ enquanto a carteira do índice Ibovespa encerrou o ano rentabilizando somente $11,69 \%$.

\subsection{Relação das carteiras com o índice Bovespa}

Grande parte dos investimentos em ações tenta representar algum dos índices de carteiras teóricas de ações. O mais utilizado no mercado brasileiro é o índice Ibovespa que é formado pelos ativos com maior volume de negócios da bolsa brasileira. Em um mercado perfeito, livre de emolumentos e taxas de corretagem, para obtermos o mesmo retorno do índice seria preciso apenas replicar em um portfólio os ativos que compõem o índice.

Como a grande maioria dos investidores convive com uma realidade diferente e com recursos escassos para investimento, os portfólios têm que se limitar somente a parte dos ativos disponíveis para negociação.

Como foi demonstrado neste trabalho, o resultado financeiro acumulado do período em estudo da carteira, superou o resultado financeiro da carteira teórica Ibovespa. O número de ativos no portfólio variou de 2 a 5 enquanto, no mesmo período, enquanto o numero de empresas listadas na composição do índice Ibovespa variou de 48 a 60. A constatação de um resultado financeiro superior ao próprio índice demonstra a eficiência das teorias aplicadas. 
Em nosso estudo foram desconsiderados os custos de transação envolvidos no processo de formação das carteiras, caso contrário esta diferença no resultado financeiro seria consideravelmente superior, pois nestas carteiras estaríamos transacionando um número entre três e cinco ativos, enquanto na representação da carteira teórica seriam em torno de sessenta ativos.

\section{Considerações finais}

O objetivo principal deste trabalho foi aplicar as teorias de Benjamin Graham para a seleção de ativos e de Harry Markowitz na composição do portfólio com base nos ativos disponíveis na principal bolsa de valores do Brasil (BM\&FBovespa) e avaliar os resultados financeiros. As aplicações destas teorias possuem a vantagem de serem acessíveis a qualquer administrador financeiro, sem a necessidade de softwares específicos, visto que no estudo foram utilizadas as funções da planilha Excel. Conforme está demonstrado neste estudo foi possível montar um portfólio com numero menor de ativos cuja rentabilidade foi superior ao índice Ibovespa. O desempenho pode ser ainda superior se forem considerados os custos de transação na adequação dos portfólios, pois a carteira do Ibovespa é composta de um número superior de ações (entre 48 e 60 no período estudado) enquanto que a composição deste estudo variou de 2 a 5, o que reduziria os custos de transação.

Este estudo é importante sob muitos aspectos. O primeiro diz respeito a aplicação de duas teorias complementares, mesmo que criadas em épocas distintas, se mostraram eficientes para a gestão de investimentos.

O segundo está relacionado a gestão de recursos. O índice Ibovespa é um indicativo do mercado brasileiro e serve como referencia para o mercado de renda variável. Com base nos resultados comprovamos que, com um numero menor de ativos, é possível obter rendimentos superiores ao benchmark do mercado.

Outro aspecto está relacionado com os custos de transação. Se os resultados forem apurados considerando estes custos, a rentabilidade da carteira seria superior devido ao menor numero de ativos negociados.

Outro ponto importante é mostrar aos pequenos investidores que a aplicação destas teorias pode ser feita de forma simplificada e pode ser um fator importante em momentos de crise, pois mesmo que estas sejam imprevisíveis, ter um método de investimentos com base nestas teorias pode ser um diferencial entre a realização de prejuízo e obtenção de lucros.

Sob o aspecto acadêmico este artigo ajuda no debate sobre a aplicação das teorias no mercado brasileiro. Contrariando alguns dos estudos anteriores sobre Markowitz, esse estudo mostra a eficiência na aplicação das teorias e os resultados são significativamente superiores aos indicadores utilizados. Da mesma forma, este estudo confirma estudos prévios sobre a aplicabilidade do estudos de Graham.

Este estudo está limitado ao Brasil e as empresas que compõem o índice Ibovespa, a inclusão de ativos com menor liquidez poderá s resultados. Assim como, replicar este estudo em outros países poderá gerar resultados diferentes dos que foram obtidos neste estudo.

Este trabalhou estudou a aplicação das teorias por um período de 5 anos com uma crise financeira mundial no meio deles. A ampliação do prazo de análise poderá chegar a outras conclusões.

Futuros estudos poderão abordar a importância dos filtros utilizados na seleção dos ativos e apontar qual deles é mais relevante na composição da carteira.

Outro estudo pode contemplar se os resultados serão iguais se a carteira for atualizada a cada quatro meses juntamente com a carteira teórica que ajuste o índice Ibovespa.

Os resultados deste estudo mostram que a teoria do portfólio ainda permite novas abordagens que auxiliem a ampliar os horizontes das finanças. 


\section{Referências}

ARTUSO, Alysson R; CHAVES NETO, Anselmo (2010) O uso de Quartis para a Aplicação dos Filtros de Graham na Bovespa (1998-2009). Revista Contabilidade \& Finanças, 52 (21). São Paulo.

ASSAF NETO, Alexandre (2003). Mercado Financeiro. 5 ed. São Paulo: Atlas.

BOVESPA . Histórico de pessoas físicas. Disponivel em:

http://www.bmfbovespa.com.br/pt-br/mercados/acoes.aspx?idioma=pt-br/histórico $\quad$ de pessoas físicas. Acesso em 07 de agosto de 2012

ELTON, Edwin j.;GRUBER, Martin J.; BROWN Stephen J.; GOETZMANN, WILLIAM N. (2004) Moderna Teoria de Carteiras e Análise de Investimentos. São Paulo:Atlas.

GRAHAM, Benjamin. (2007) O Investidor Inteligente. 4.ed rev. Rio de Janeiro:Nova Fronteira.

GRAHAM, Benjamin. (1973) The Intelligent Investor. New York: Harper Business, 1973

MARKOWITZ, Harry M. (1991) Portfolio Selection:Efficient diversification of investment. 2.ed. Massachussets: Blackwell Publishers.

NAKAMURA, Wilson T. (2000) Estudo Empírico Sobre a Eficiência da Carteira Teórica do Índice Bovespa. Revista de Administração Mackenzie, 1 (1).

PASSOS, V. C. S. (2006) Estratégias de investimento em Bolsa de Valores: uma pesquisa exploratória da visão fundamentalista de Benjamin Graham. Dissertação. Faculdade de Ciências Humanas de Pedro Leopoldo, Pedro Leopoldo.

PASSOS,Vinicius de C. S. dos e PINHEIRO Juliano L. (2009) Estratégias de Investimento em Bolsa de Valores: Uma Pesquisa Exploratória da Visão Fundamentalista de Benjamin Graham. Revista Gestão \& Tecnologia, 1 (9).

SALGUEIRO (2007) SALGUEIRO, G. C. Comparação das filosofias de investimento de Benjamin Graham e Warren Buffett: aplicação no mercado brasileiro. Trabalho de Conclusão de Curso.Universidade de São Paulo, São Paulo.

SCHROEDER, Alice. (2008) A Bola de Neve. Rio de Janeiro: Sextante.

SILVA, Marcos Eugênio da, STERN, Julio M.(1995) Efficient Portfólios at São Paulo Stock Exchange (Bovespa) in 1994, XVII Encontro Brasileiro de Econometria - Anais- p. 9951013.

ZANINI, Francisco A.M; FIGUEIREDO, Antonio C.(2005) As Teorias de Carteira de Markowitz e de Sharpe: Uma Aplicação no Mercado Brasileiro de Ações entre Julho/95 e Junho/2000. Revista de Administração Mackenzie 6 (2)

VINCE, Ralph (1999) Cálculo e Análise de Riscos no Mercado Financeiro. São Paulo: Makron Books.

VINCE, Ralph (2004) The New Money Management: a framework for asset allocation. New York; Wiley 